\title{
Ueber die Oxydation des Phosphors durch Salpeter-
} säure.

Reinsch hat über diesen Gegenstand Versuche angestellt und folgende Schlussfolgerungen gezogen:

1) Der Phosphor wird bei Zutritt der atmosphärischen Luft und bei niedriger Temperatur von Salpetersäure nur wenig angegriffen, indem er sich mit einer Schicht Oxyd überzieht.

2) Bei Abschluss der atmosphärischen Luft und niedriger Temperatur entwickelt sich bei Einwirkung der Salpetersäure auf Phosphor reines Stickstoffoxydgas und die Salpetersäure färbt sich blau, die Oxydation schreitet fort, olne dass sich der Phosphor mit Oxyd iiberzieht.

3) Die kochende Salpetersäure wirkt bei abgeschlossener Luft so auf den Phosphor, dass sich auch das entwickelnde Stickstoffoxyd fast vollkommen in Sauerstoff, welcher von dem Phosphor aufgenommen wird, und in Stickgas zersetzt.

4) Bei Mitwirkung der atmosphärischen Luft während der Oxydation des Phosphors durch kochende Salpetersäure wird das Stickstoffoxydgas nicht zersetzt, sondern die Atmosphäre gielst einen Theil Sauerstoff, zur Oxydation des Phosphors her und verwandelt jenes Gas in salpetrige Säure.

5) Eine mit ihrem gleichen Gewichte Wasser verduinnte Salpetersäure wirkt auf den Phosphor bei Kochhitze nur sehr schwach; es bildet sich dabei kein Phosphorwasserstoffgas. (Journal für prakit. Chemie. Bd. XXVIII. 7. u. 8. Ifft.)

\section{Bereitung der Salpetersäure aus Chilisalpeter; nach II. O enicke.}

Der sogenannte Chilisalpeter enthält ausser salpetersaurem Natron mehrere andere Salze, namentlich Chlornatrium. Letzteres ist oft sehr störend bei der Bereitung der Salpetersäure, namentlich wenn es, wie so oft, in beträchtlicher Menge darin enthalten ist. Es entwickeln sich nämlich bei der gleichzeitigen Einwirkung der Schwefelsäure auf salpetersaures Natron und Chlornatrium, grosse Quantitäten von Chlor und salpetrigsaurem Gase. Da ihre Mengen so gross sind, dass sie selbst bei der sorgfältigsten Abkühlung, nicht von der. überdestillirenden llüssigen Säure absorbirt werden können, so belästigen sie den Arbeiter auf hüchst unangenehme Weise. Um diesen tebelstande 
abzuhelfen, verfährt man folgendermassen: Man wählt zu der Bereitung der Salpetersäure eine Retorte mit so langem Halse, dass derselbe bis in die Kugel des vorzulegenden Kolbens reicht. Der Hals des Kolbens muss um die Retorte ziemlich gut schliessen, und muss 'zweitens tubulirt sein. In den Tubus befestigt man mittelst eines Stöpsels von Speckstein eine Glasröhre, welche die sich entwickelnden Gase ab und zwar am Besten in den Schornstein der Feuerung leitet. Man lutirt gut, und kann nun die Kugel des Kolbens so gut abkiihlen, dass man die grösste mögliche Menge an Salpetersaure erhält. (Pharm. Centralbl. No. 22. pag. 351.)

\section{Bereitung des Chlorwassers; von $\mathrm{H}$. $\mathrm{O}$ e nick e.}

Die Bereitung des Chlorwassers, wie sie die preussische Pharmakopüe angiebt, ist mit einigen Uebelständen verknüpft. Namentlich ist das Einathmen des Chlorgases dabei fast unvermeidlich (?), welches man jedoch fast gänzlich vermeiden kann, wenn man folgendermassen verfährt: Man wählt zur Bereitung des Chlorwassers einen Wintertag, und füllt eine Flasche zu drei Viertel ihres Inhalts mit destillirtem Wasser von +2 bis $3^{v} \mathbf{R}$. Auf den Boden dieser Flasche leitet man nun das gewaschene Chlorgas und zwar mittelst einer etwas weiten Röhre, weil sie sich sonst verstopfen würde. Das ausströmende Gas wird vollständig absorbirt, und bei der niedrigen Temperatur bildet sich sogleich Chlorhydrat, welches sich in krystallinischen Blättchen am Boden sammelt. Hat sich eine beträchtlicho Quantität Hydrat gebildet, so schuittelt man die Flasche um. Das Chlorhydrat löst sich auf, man leitet von Neuem Chlorgas hinein, schiittelt wieder, und wiederholt dieso Operation so lange, bis Chlorhydrat ungelöst zuriickbleibt Das Wasser enthält nun die grösstmögliche Menge Chlor; man lässt absetzen und giesst die klare Flüssigkeit von dem ungelösten Hydrat ab. Dass diese ganze Arbeit im Freien ausgefiuhrt werden muss, darf nicht erst erwähnt werden. (Pharm. Centralbl. No. 22. pag. 352.)

\section{Verhalten des Queclisilberoxyds zu Chlorcalcium; von Hochsietter.}

Die Eigenschaft einer Auflösung von Chlormagnesium, durch Quecksilberoxyd in Quecksilberchlorid und reine Yagnesia zersetzt zu werden, gicbt bekauntlich ein ein- 